Article

\title{
Bronsted and Lewis Solid Acid Catalysts in the Valorization of Citronellal
}

\author{
Federica Zaccheria ${ }^{1}$, Federica Santoro ${ }^{1}$, Elvina Dhiaul Iftitah ${ }^{2}$ and Nicoletta Ravasio ${ }^{1, *}$ \\ 1 CNR Institute of Molecular Science and Technology, Via Golgi 19, 20133 Milano, Italy; \\ f.zaccheria@istm.cnr.it (F.Z.); f.santoro@istm.cnr.it (F.S.) \\ 2 Chemistry Department Faculty of Science, Brawijaya University Jl. Veteran, Malang 65145, Indonesia; \\ vin_iftitah@ub.ac.id \\ * Correspondence: n.ravasio@istm.cnr.it; Tel.: +39-02-5031-4382
}

Received: 30 July 2018; Accepted: 12 September 2018; Published: 22 September 2018

check for updates

\begin{abstract}
Terpenes are valuable starting materials for the synthesis of molecules that are of interest to the flavor, fragrance, and pharmaceutical industries. However, most processes involve the use of mineral acids or homogeneous Lewis acid catalysts. Here, we report results obtained in the liquid-phase reaction of citronellal with anilines under heterogeneous catalysis conditions to give tricyclic compounds with interesting pharmacological activity. The terpenic aldehyde could be converted into octahydroacridines with a $92 \%$ yield through an intramolecular imino Diels-Alder reaction of the imine initially formed in the presence of an acidic clay such as Montmorillonite KSF. Selectivity to the desired product strongly depended on the acid sites distribution, with Brønsted acids favoring selectivity to octahydroacridine and formation of the cis isomer. Pure Lewis acids such as silica-alumina with a very low amount of alumina gave excellent results with electron-rich anilines like toluidine and p-anisidine. This protocol can be applied starting directly from essential oils such as kaffir lime oil, which has a high citronellal content.
\end{abstract}

Keywords: solid acids; acidic clays; terpenes; citronellal; octahydroacridines; heterogeneous catalysis

\section{Introduction}

Terpenes represent a class of natural compounds suited for the synthesis of several types of molecules useful for the industrial production of intermediates for fragrances, flavors, and pharmaceuticals [1]. $\alpha$-pinene, e.g., one of the main components of turpentine, can be used as a starting material for the synthesis of $\beta$-santalol and sandalwood fragrances. These are valuable alternatives to toxic nitro-musks and low-biodegradability polycyclic musks that are among the commonly used fragrances in European laundry detergents, fabric softeners, cleaning agents, and cosmetic products, therefore ubiquitously present in the aquatic environment [2].

In previous years, the use of terpenes has been widely investigated in the polymer industry because of the strong need for renewable and biodegradable materials in this sector [3,4].

Among terpenic molecules, citronellal, citral, limonene, carene, and pinene are common because of their large occurrence in essential oils and in oils derived from agro-industrial residues. Citronellal and citral offer noteworthy opportunities in synthetic strategies because of their condensation and addition reactions by virtue of their unsaturated aldehydic structure. The abundance of these two molecules in essential oils such as kaffir lime, citronella, lemongrass, and krangean oil, promotes their use as raw materials for the sustainable synthesis of different chemicals, specifically N-containing ones. A Schiff base with antibacterial activity was recently synthesized through acid catalysis from citronellal, [5] while benzimidazole derivatives of both aldehydes were obtained by using microwave irradiation [6]. In this case, the aldehyde reacts with $o$-phenylenediamine to give the benzimidazol 
moiety, but when an aromatic monoamine reacts with an unsaturated aldehyde it gives an $\mathrm{N}$-aryl imine that can further react with the electron-rich alkene moiety through the Povarov reaction, which is an intramolecular imino Diels-Alder reaction [7] (Scheme 1).

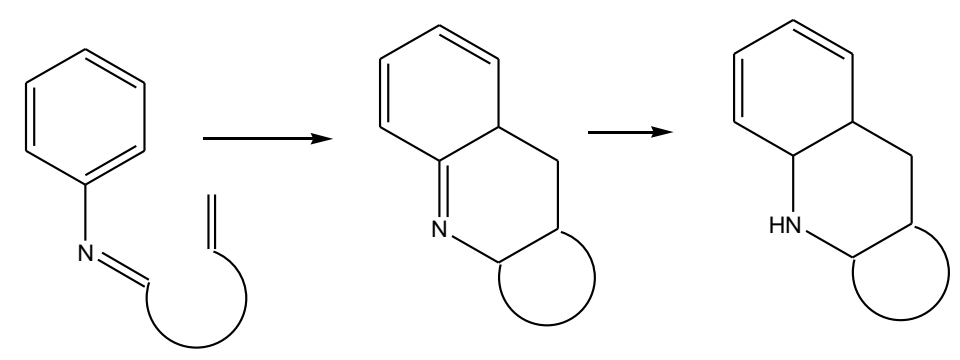

Scheme 1. General intramolecular Povarov reaction.

This class of organic reactions has attracted interest as a useful route of access to $\mathrm{N}$-containing polycyclic structures, such as substituted tetrahydroquinoline and octahydroacridine (OHAs) derivatives. Octahydroacridine systems are an interesting class of biologically active molecules in the field of drugs and pharmaceuticals, acting as gastric acid secretion inhibitors [8] in the prevention of senile dementia [9].

Despite several varying methods available offering access to the octahydroacridine skeleton, such as the Beckmann rearrangement of oxime sulfonate, [10] the catalytic hydrogenation of acridine, [11] and Friedel-Crafts acylation, [12] the simplest one remains the acid catalyzed imino Diels-Alder reaction of 2-azadienes. Because of their poor reactivity in the Povarov reaction, 2-azadienes need to be activated through coordination with acidic catalysts that enhance their electron-deficient character. Both Lewis and Brønsted acids have been used, but, despite their effectiveness, many of these catalysts show disadvantages, such as multistep procedures, long reaction times, use of inert atmosphere, expensiveness, and tedious work-up. Therefore, developing green and efficient catalysts for this reaction is an important challenge.

An efficient synthesis of OHAs starts from citronellal and N-arylamines [13,14] (Scheme 2). This Lewis-acid catalyzed imino Diels-Alder reaction is the most atom-economic way to OHAs, with high yields and, in some cases, high stereoselectivity.

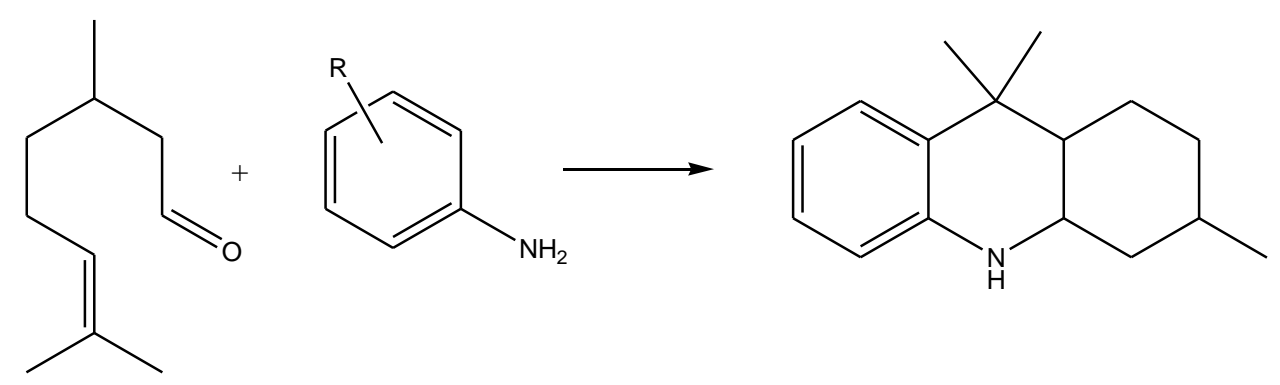

Scheme 2. Reaction of citronellal and anilines into the corresponding octahydroacridine.

During our recent studies on reductive amination of ketones, [15] the attempts to synthesize amine derivatives of $\mathrm{C}=\mathrm{O}$-containing terpenes led us to obtain $\mathrm{OHAs}$ structures. Herein, we report our results about the synthesis of OHAs from citronellal promoted by solid acid catalysts.

\section{Results and Discussion}

Previously, we have reported on the use of pre-reduced $\mathrm{Cu} / \mathrm{SiO}_{2}(\mathrm{Cu} / \mathrm{Si})$ catalysts in the Direct Reductive Amination (DRA) of aromatic ketones [15]. This is a significant reaction allowing one to obtain secondary amines in one step starting from a ketone, which is still carried out in the presence of unfavorable reagents such as $\mathrm{NaBH}_{3} \mathrm{CN}$ or $\mathrm{NaBH}(\mathrm{OAc})_{3}$. The use of a heterogeneous catalyst 
based on a non-noble metal can yield up to $98 \%$ of the amine at $100{ }^{\circ} \mathrm{C}$ in a few hours. Unfortunately, under the same conditions, aliphatic terpenic ketones, in particular menthone, a major component of dementholized mint oil, react slowly, requiring a longer time span, although selectivity to the amine is excellent (Scheme 3).

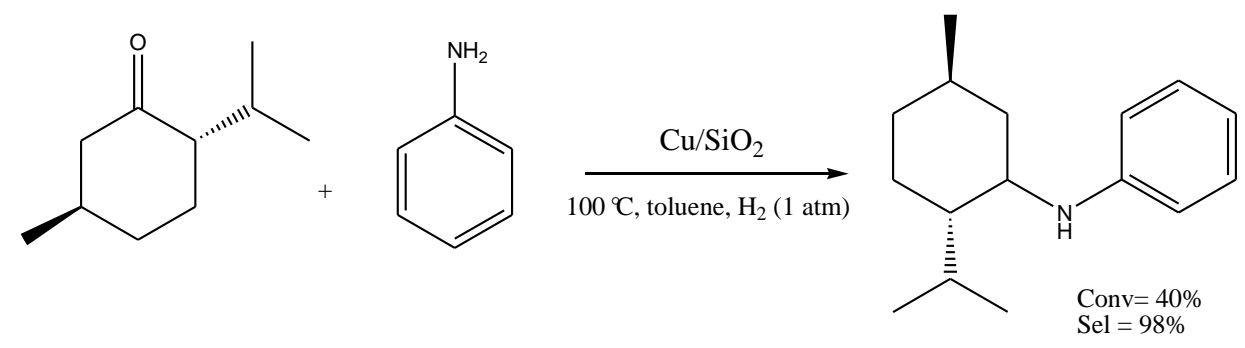

Scheme 3. Amination of menthone with aniline (Conv = Conversion; Sel = Selectivity).

This prompted us to test the reaction of terpenic molecules with a greater number of reactive aldehyde groups.

Table 1 reports selected results obtained in the reaction of citronellal under varying conditions and in the presence of several catalytic materials.

Surprisingly, the reaction of citronellal with aniline under DRA conditions, that is, in the presence of pre-reduced $\mathrm{Cu}$ catalyst and molecular $\mathrm{H}_{2}$, was quick and gave the corresponding $\mathrm{OHA}$ as the only product in high yield (Table 1, entry 3). A blank test carried out without a catalyst led to the formation of the intermediate imine, without observing the formation of the Diels-Alder product, showing that, in this specific reaction, a catalyst is only necessary for the second step, and a reductive environment is not required (Table 1, entries 1-2). Therefore, both pre-reduction of the catalyst and molecular $\mathrm{H}_{2}$ could be avoided, and the unreduced $\mathrm{CuO} / \mathrm{SiO}_{2}(\mathrm{CuO} / \mathrm{Si})$ catalyst was used at room temperature in the presence of air, giving comparable results.

This reactivity is ascribed to the Lewis acid character of $\mathrm{CuO} / \mathrm{SiO}_{2}$. Thus, the chemisorptionhydrolysis technique used in the preparation of this catalyst allows us to reach a high dispersion of $\mathrm{CuO}$ on the silica surface [16]. The $\mathrm{CuO}$ particles are small and defective, thus giving an account of the Lewis acidity of this material, able to promote, e.g., the ring opening of epoxides with alcohols [17]. After the reduction pre-treatment, highly defective metal nanoparticles are formed showing Lewis acid activity in a wide range of reactions, particularly in the one-pot production of valeric esters from $\gamma$-valerolactone (GVL) and alcohols [18].

Therefore, other solid acids can be used in the synthesis of OHA. Because of our experience in the use of amorphous mixed oxides, we tested some of them in this reaction, namely, a silica-alumina cracking catalyst with a $13 \%$ content of $\mathrm{Al}_{2} \mathrm{O}_{3}$ ( $\mathrm{SiAl} 13$ ) and a $0.6 \%$ Alumina on silica (SiAl0.6). Furthermore, we also tested two commercial acid-treated clays, namely, Montmorillonite K10 and KSF. Clays are versatile materials widely used for various applications, including catalytic ones. Thus, increasingly stringent environmental issues and process optimization call for the substitution of liquid acids by more sustainable solid materials. Clays have both Brønsted (B) and Lewis (L) sites, the amount and the strength of which can be modified by acid treatment. Commercial acid-treated clays are widely used industrially as acid catalysts, therefore they are well-defined and reliable materials. K10 is commonly used in the formation of a $\mathrm{C}-\mathrm{N}$ bond as an alternative to $\mathrm{HCl}$, e.g., in the synthesis of alkylquinolines [19].

It should be emphasized that, under acidic conditions, citronellal can undergo the ene reaction to give isopulegol (Scheme 4). Although this is an interesting reaction, as isopulegol can be hydrogenated to menthol, in the present case this is a secondary reaction that lowers the yield in OHA and, therefore, a fine-tuning of the acidity is mandatory in order to reach a high selectivity to the desired product. 


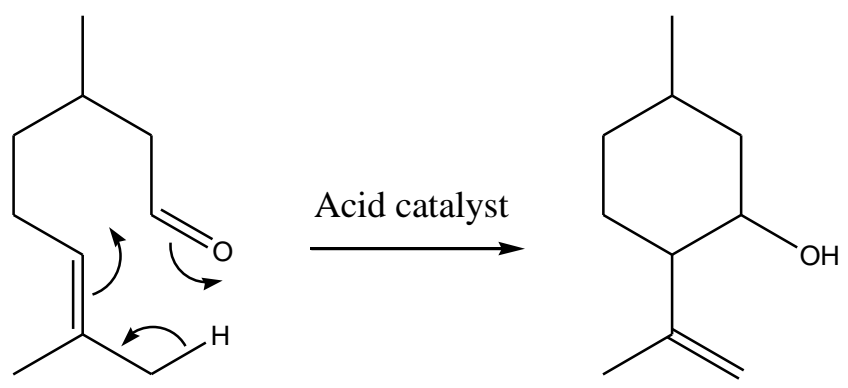

Scheme 4. Ene reaction of citronellal into isopulegol.

Results reported in Table 1 show significant differences in selectivity. Considering the reaction between citronellal and aniline, the two amorphous silica-aluminas and Montmorillonite K10 gave a low yield in OHA due to a significant formation of isopulegols (Table 1, entries 6,11,13). This agrees with our previous findings [20], showing that these three catalysts are highly active in the cyclization of citronellal to isopulegol. However, moving from aniline to electron-rich amines, the selectivity to OHA increased, reaching a remarkable $96 \%$ yield in the case of p-anisidine over the catalyst with a very low amount of alumina (Table 1, entry 9).

Table 1. Synthesis of octahydroacridines starting from ( \pm )-Citronellal and anilines.

\begin{tabular}{|c|c|c|c|c|c|c|c|c|c|}
\hline Entry & Catalyst & Amine & Conditions & Th & Conv. $\%$ & OHAs Sel \% & Cis/Trans. & Imine Sel \% & Isopulegols \% \\
\hline \multirow{2}{*}{1} & \multirow{2}{*}{ None } & \multirow{2}{*}{ aniline } & \multirow{2}{*}{ Toluene, $100^{\circ} \mathrm{C}, \mathrm{N}_{2}$} & 1 & 73 & \multirow[t]{2}{*}{-} & \multirow[t]{2}{*}{-} & 87 & \multirow[t]{2}{*}{ - } \\
\hline & & & & 7.5 & 96 & & & 93 & \\
\hline 2 & None & aniline & Heptane, $25^{\circ} \mathrm{C}$, air & 1 & 96 & - & - & 83 & - \\
\hline 3 & $\mathrm{Cu} / \mathrm{Si}$ & aniline & Toluene, $100{ }^{\circ} \mathrm{C}, \mathrm{H}_{2}$ & 1 & $>99$ & 97 & $37 / 63$ & $<1$ & 1 \\
\hline 4 & $\mathrm{CuO} / \mathrm{Si}$ & aniline & Toluene, $25^{\circ} \mathrm{C}$, air & 1 & $>99$ & 96 & $45 / 55$ & - & 2 \\
\hline 5 & $\mathrm{CuO} / \mathrm{Si}$ & p-anisidine & Toluene, $25^{\circ} \mathrm{C}$, air & 1 & $>99$ & 59 & $61 / 39$ & - & 32 \\
\hline 6 & SiAl 0.6 & aniline & Heptane, $25^{\circ} \mathrm{C}$, air & 1 & $>99$ & 71 & $41 / 59$ & $<1$ & 24 \\
\hline 7 & SiAl 0.6 & aniline & Heptane, $0^{\circ} \mathrm{C}$, air & 1 & $>99$ & 79 & $49 / 51$ & - & 17 \\
\hline 8 & SiAl 0.6 & aniline & Dioxane, $25^{\circ} \mathrm{C}$, air & 1 & $>99$ & 82 & $58 / 42$ & - & 14 \\
\hline 9 & SiAl 0.6 & p-anisidine & Heptane, $25^{\circ} \mathrm{C}$, air & 1 & $>99$ & 96 & $51 / 49$ & $<1$ & 2 \\
\hline 10 & SiAl 0.6 & toluidine & Heptane, $25^{\circ} \mathrm{C}, \mathrm{N}_{2}$ & 2 & $>99$ & 90 & $37 / 63$ & - & 1 \\
\hline 11 & SiAl 13 & aniline & Heptane, $25^{\circ} \mathrm{C}, \mathrm{N}_{2}$ & 1 & $>99$ & 64 & $41 / 59$ & - & 23 \\
\hline 12 & SiAl 13 & aniline & Heptane, $0^{\circ} \mathrm{C}$, air & 1 & $>99$ & 86 & $58 / 42$ & - & 11 \\
\hline 13 & Mont K10 & aniline & Heptane, $25^{\circ} \mathrm{C}$, air & 1 & $>99$ & 70 & $55 / 45$ & - & 14 \\
\hline 14 & Mont KSF & aniline & Heptane, $25^{\circ} \mathrm{C}$, air & 1 & $>99$ & 92 & $71 / 29$ & - & 5 \\
\hline 15 & Mont KSF & aniline & Heptane, $0^{\circ} \mathrm{C}$, air & 1 & $>99$ & 85 & $73 / 27$ & - & 10 \\
\hline
\end{tabular}

It is worth emphasizing that only Lewis acid sites could be detected on the surface of SiAl0.6, as shown by FT IR spectra of adsorbed pyridine, while the other solids used showed also Brønsted acid sites (Table 2). OHA: octahydroacridine.

Table 2. Quantitative determination of acidic sites versus products distribution in the reaction of citronellal with aniline.

\begin{tabular}{llclll}
\hline Catalyst & \multicolumn{1}{l}{ Acidic Sites $\left(\mathbf{m m o l}_{\text {py } / \text { gcat }}\right)$} & \% OHA & \% Cis & \% Isopulegols \\
\hline KSF & 0.157 & 0.025 & 92 & 71 & 5 \\
K10 & 0.077 & 0.042 & 70 & 55 & 14 \\
SiAl13 & 0.039 & 0.163 & 64 & 41 & 23 \\
SiAl 0.6 & - & 0.005 & 71 & 41 & 24 \\
\hline
\end{tabular}


Figure 1 shows the comparison of the two amorphous silica-alumina catalysts and the two clays: it is evident that both Brønsted and Lewis sites were present on the surface of the catalyst containing $13 \%$ of alumina and on the two clays, whereas the Brønsted ones were absent on the low-loading one.

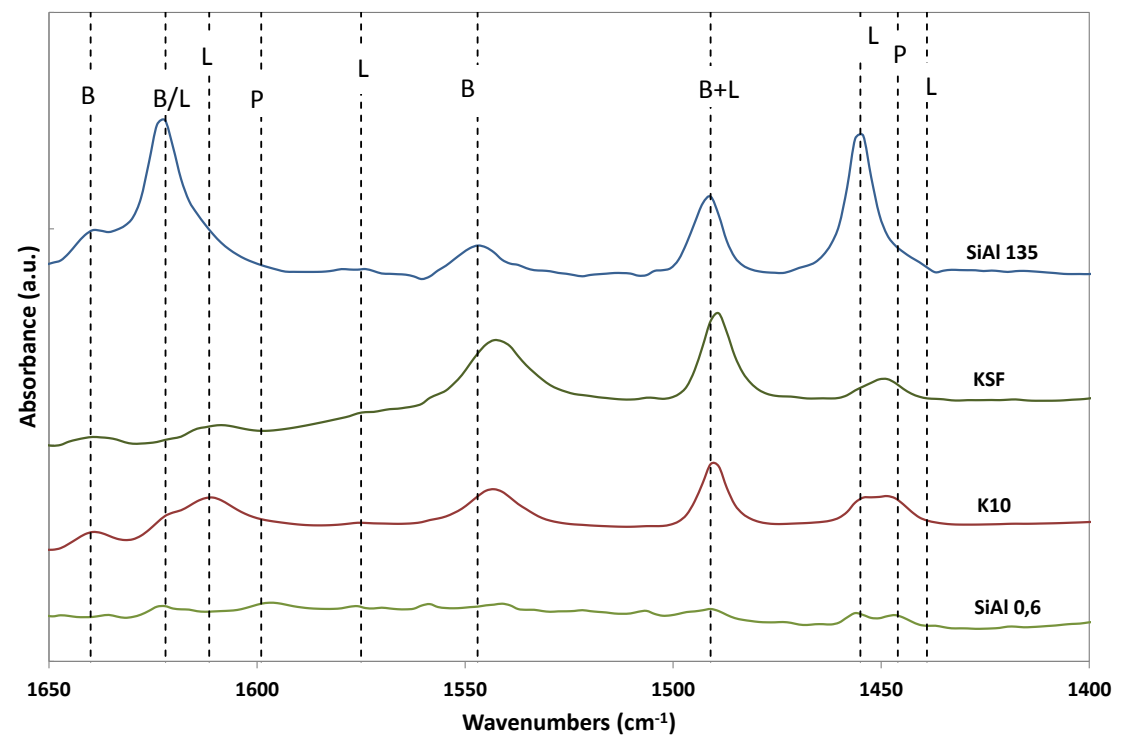

Figure 1. FTIR spectra of pyridine adsorbed on the silica-alumina catalysts: $P=$ physisorbed, $\mathrm{B}=$ Brønsted sites, $\mathrm{L}=$ Lewis acid sites.

Thus, in SiAl 13, the bands at $1640 \mathrm{~cm}^{-1}, 1547 \mathrm{~cm}^{-1}$, and $1492 \mathrm{~cm}^{-1}$ are the intense modes of pyridinium cations associated with a total proton transfer from the Brønsted acidic surface $\mathrm{OH}$ group to the basic molecule, whereas the bands at $1623 \mathrm{~cm}^{-1}$ and $1455 \mathrm{~cm}^{-1}$ are due to the pyridine molecularly coordinated on $\mathrm{Al}^{3+}$ cations, acting as Lewis acid sites [21].

However, the spectra of pyridine adsorbed on clays, KSF, and K10, showed the presence of both Lewis and Brønsted sites, although the former in lower concentration.

The presence of weak absorption bands at $1545 \mathrm{~cm}^{-1}, 1490 \mathrm{~cm}^{-1}$, and $1450 \mathrm{~cm}^{-1}$, indicating the presence of both Brønsted and Lewis acidity in low concentrations, has already been reported, although in the Diffuse Reflectance Infrared Fourier Transform (DRIFT) spectra of pyridine adsorbed on the surface of montmorillonite K10 [22], while the presence of medium-weak Brønsted sites and strong Lewis sites was evidenced by a range of complementary experimental techniques by Lenarda et al. [23]. However, the number of these sites has never been quantified. Table 2 shows that $B$ sites in KSF are twice the number of those in $\mathrm{SiAl} \mathrm{13,} \mathrm{that} \mathrm{in} \mathrm{turn} \mathrm{are} \mathrm{twice} \mathrm{the} \mathrm{number} \mathrm{of} \mathrm{those} \mathrm{in} \mathrm{K10,}$ in agreement with previous determinations through $\mathrm{NH}_{3}$ chemisorption of acidic sites in KSF and K10 [24].

Comparing the results obtained with the relative number of acidic sites reported in Table 2, it is apparent that, for catalysts containing both B and L sites, the yield in OHA increases with the number of $B$ sites, while the amount of isopulegols increases with the number of $L$ sites (Figure 2).

The catalyst that contains only L sites showed an intermediate behavior, giving only $71 \%$ of $\mathrm{OHA}$ in the reaction of citronellal and aniline (Table 1, entry 6). However, by increasing the electro-donor ability of the substituent, this catalyst gave excellent results, reaching a $96 \%$ yield in the reaction with anisidine (Table 1, entry 9).

According to our results, differences in acidity can also influence products stereochemistry. 
A

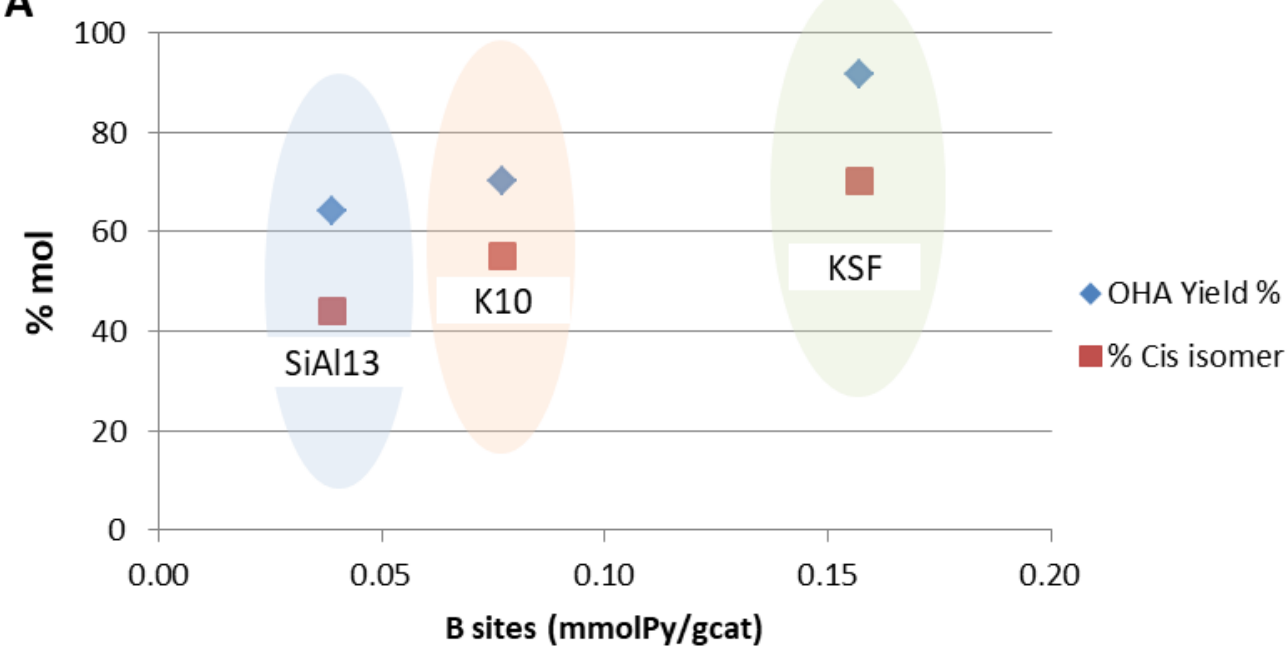

B

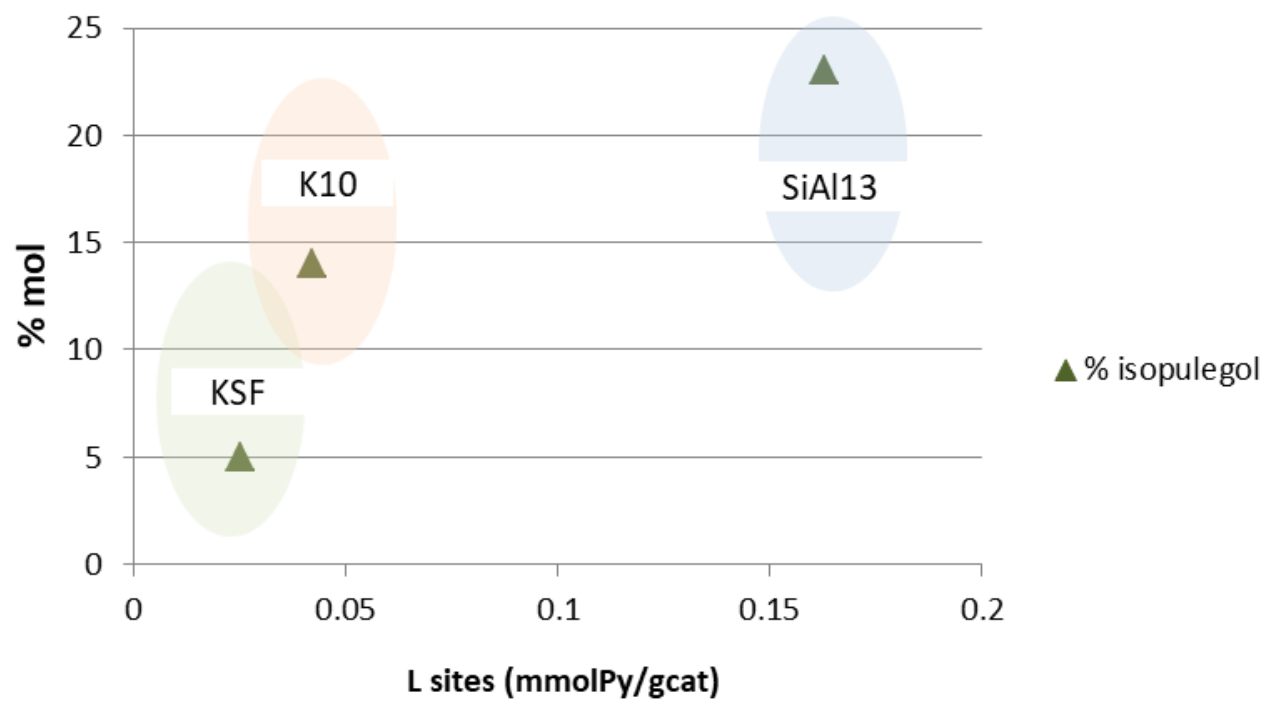

Figure 2. Trend in products distribution versus the concentration of B acidic sites (A) and L sites (B).

Laschat and Lauterwein [25] reported on the use of several homogeneous Lewis acids at $-78{ }^{\circ} \mathrm{C}$ in $\mathrm{CH}_{2} \mathrm{Cl}_{2}$ and drew the conclusion that the catalyst plays only a minor role in determining the cis/trans ratio. In agreement with this work, Kouznetsov [26] found that the bulkiness of the aniline derivative has a pivotal role when both Lewis and Brønsted acids are used as a catalyst, allowing to reach $97 \%$ of the trans isomer for the N-benzyl-aniline derivative at room temperature. However, in the presence of $\mathrm{TiCl}_{3}$, the cis/trans ratio did not change significantly by changing the amine [9].

Reports on heterogeneous catalysts in this specific reaction are rare; $\mathrm{ZnCl}_{2}$ supported on silica was used in the presence of microwaves, giving a 78\% yield in the case of aniline, with a cis/trans ratio of 1:1 [13]. The introduction of electron-donor or electron-withdrawer substituents on the aniline moiety influenced both yield and stereochemistry of the products.

In the present case, differences in stereochemistry are evident. Specifically, pure Lewis solids (both $\mathrm{CuO} /$ silica and $\mathrm{SiAl} \mathrm{0.6)}$ promote 40/60 mixtures with a slight excess of trans isomers. When introducing $\mathrm{B}$ acid sites, the number of cis isomers increases, and the solid with a more prominent B acid character, namely, KSF, favors the formation of the cis-isomer (Table 1, entries 14 and 15, Figure 2A). This could be because of the different adsorption of the intermediate imine on the catalyst surface, with Brønsted sites binding strongly to the $\mathrm{N}$ atom and favoring the transition state leading to the cis isomer. 
The solid catalyst is also reusable, allowing to obtain the desired OHA product, although in lower yield $(75 \%)$ under non-optimized conditions, such as without washing the catalyst.

This protocol can be successfully applied directly to essential oils. Thus, the reaction of kaffir lime oil with aniline in heptane and in the presence of clay KSF produced an oil containing $70 \%$ of octahydroacridine in one hour (Scheme 5).

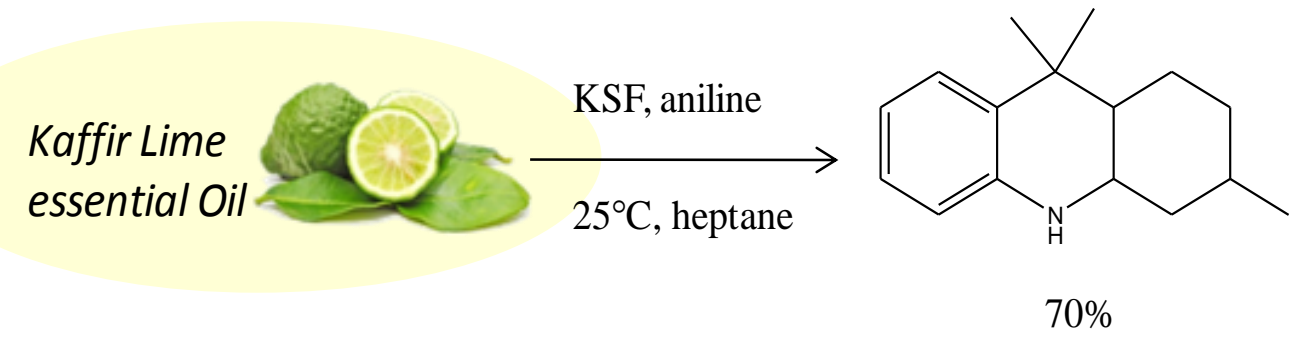

Scheme 5. Octahydroacridine formation, starting directly from kaffir lime.

\section{Experimental Section}

\subsection{Materials and Methods}

$( \pm)$-Citronellal (>95\%), aniline (>99\%), $p$-anisidine ( $>99 \%)$ and toluidine $(99 \%)$ were purchased from Sigma-Aldrich (Milan, Italy) and used without pretreatment. Kaffir lime (Citrus hystrix D.C) oil was obtained from the Essential Oil's Institute Atsiri, Brawijaya University, Malang (RI).

$\mathrm{SiO}_{2}-\mathrm{Al}_{2} \mathrm{O}_{3} 13$ (Surface Area $=485 \mathrm{~m}^{2} / \mathrm{g}$, Pore Volume $=0.79 \mathrm{~mL} / \mathrm{g}$ ), was purchased from Sigma-Aldrich; $\mathrm{SiO}_{2}-\mathrm{Al}_{2} \mathrm{O}_{3} 0.6$ (Surface Area $=483 \mathrm{~m}^{2} / \mathrm{g}$, Pore Volume $=1.43 \mathrm{~mL} / \mathrm{g}$ ) was kindly provided by GRACE Davison. Montmorillonite KSF and Montmorillonite K10 were purchased from Sigma-Aldrich; $\mathrm{SiO}_{2}$ (Surface Area $=460 \mathrm{~m}^{2} / \mathrm{g}$, Pore Volume $=0.74 \mathrm{~mL} / \mathrm{g}$ ) was purchased from Fluka (Milan, Italy).

\subsection{Copper Catalyst Preparation}

$\mathrm{CuO} / \mathrm{SiO}_{2}$ (with $16 \%$ of copper loading) catalyst was prepared by the chemisorption-hydrolysis technique as reported [16], by adding the support to an aqueous $\left[\mathrm{Cu}\left(\mathrm{NH}_{3}\right)_{4}\right]^{2+}$ solution prepared by dropping $\mathrm{NH}_{4} \mathrm{OH}$ into a $\mathrm{Cu}\left(\mathrm{NO}_{3}\right)_{2} \cdot 3 \mathrm{H}_{2} \mathrm{O}$ solution until $\mathrm{pH} 9$ had been reached. After 20 min under stirring, the slurry, held in an ice bath at $0{ }^{\circ} \mathrm{C}$, was diluted with water. The solid was separated by filtration with a Büchner funnel, washed with water, dried overnight at $120^{\circ} \mathrm{C}$, and calcined in air at $350{ }^{\circ} \mathrm{C}$.

\subsection{Catalyst Characterization}

FTIR Spectra of adsorbed pyridine. The FT-IR studies of probe molecules (pyridine) adsorption and desorption were carried out with a BioRad FTS-60 (Segrate, Italy) spectrophotometer equipped with a mid-IR MCT detector. The experiments were performed on a sample disk (15-20 mg) after a simple calcination treatment $\left(180^{\circ} \mathrm{C}, 20 \mathrm{~min}\right.$ air $+20 \mathrm{~min}$ under vacuum). One spectrum was collected before probe molecule adsorption as a blank experiment. Therefore, pyridine adsorption was carried out at room temperature, and the following desorption steps were performed from room temperature to $250{ }^{\circ} \mathrm{C}$. The spectrum of each desorption step was acquired every $50{ }^{\circ} \mathrm{C}$ after cooling the sample. For quantitative analysis, the amount of adsorbed pyridine $\left(\mathrm{mmol}_{\mathrm{Py}} / \mathrm{g}_{\mathrm{cat}}\right)$ was calculated on the basis of the relationship reported by Emeis [27] from the integration of diagnostic bands evaluated in the spectra registered at $150{ }^{\circ} \mathrm{C}$.

\subsection{Catalytic Tests}

Prior to the catalytic tests, the catalysts $\left(100 \mathrm{mg}\right.$ ) were pretreated as follows: $\mathrm{SiO}_{2}-\mathrm{Al}_{2} \mathrm{O}_{3}$ was calcined for $20 \mathrm{~min}$ in air at $180^{\circ} \mathrm{C}$ and $20 \mathrm{~min}$ under vacuum at the same temperature; Montmorillonite 
$\mathrm{KSF}$ and Montmorillonite $\mathrm{K} 10$ were dried in an oven at $120^{\circ} \mathrm{C}$ for one night; $\mathrm{CuO} / \mathrm{SiO}_{2}$ was calcined for $20 \mathrm{~min}$ in air at $270{ }^{\circ} \mathrm{C}$ and $20 \mathrm{~min}$ under vacuum at the same temperature, and a following reduction step with $\mathrm{H}_{2}(1 \mathrm{~atm})$ was performed for $\mathrm{Cu} / \mathrm{SiO}_{2}$-catalyzed reactions.

In a glass reaction vessel containing the pretreated catalyst, a mixture of citronellal $(0.55 \mathrm{mmol})$ and amine $(1.66 \mathrm{mmol})$ in $5 \mathrm{~mL}$ of solvent was charged. Therefore, the reaction proceeded with the proper temperature conditions under magnetic stirring. At the desired reaction time, the mixture was separated by simple filtration from the catalysts, and the products were analyzed by GC-MS (5\%-phenyl-methyl polysiloxane column) and NMR (Bruker $500 \mathrm{MHz}$ ).

For the recycling tests, the solution was separated from the catalyst after the first run by simple decantation, and a fresh reaction mixture was charged in the reactor without treating the catalyst.

In the experiment carried out with Kaffir lime oil, a mixture containing $100 \mu \mathrm{L}$ of essential oil and $1.66 \mathrm{mmol}$ of aniline in $5 \mathrm{~mL}$ of solvent was charged in a glass reaction vessel containing $100 \mathrm{mg}$ of KSF dried overnight at $120^{\circ} \mathrm{C}$.

${ }^{1} \mathrm{HNMR}$ data (300 MHz, $\mathrm{CDCl}_{3}$ ) (See Supplementary Materials for NMR Spectra) A) cis isomer: $\delta=0.98\left(\mathrm{~d}, \mathrm{~J}=6.4,3 \mathrm{H}, \mathrm{CH}_{3}\right), 1.07-1.89\left(\mathrm{~m}, 2 \mathrm{H}, \mathrm{CH}_{2}\right), 1.13-1.97\left(\mathrm{~m}, 2 \mathrm{H}, \mathrm{CH}_{2}\right), 1.31\left(\mathrm{~s}, 3 \mathrm{H}, \mathrm{CH}_{3}\right)$, $1.33(\mathrm{~s}, 1 \mathrm{H}, \mathrm{CH}), 1.38(\mathrm{~s}, 1 \mathrm{H}, \mathrm{CH}), 1.41\left(\mathrm{~s}, 3 \mathrm{H}, \mathrm{CH}_{3}\right), 1.83(\mathrm{~m}, 1 \mathrm{H}, \mathrm{CH}), 1.86(\mathrm{~m}, 1 \mathrm{H}, \mathrm{CH}), 3.69(\mathrm{bs}, \mathrm{NH})$, $3.92(\mathrm{dt}, 1 \mathrm{H}, \mathrm{CH}), 6.51(\mathrm{dd}, 1 \mathrm{H}, \mathrm{CH}), 6.68(\mathrm{~m}, 1 \mathrm{H}, \mathrm{CH}), 7.04(\mathrm{~m}, 1 \mathrm{H}, \mathrm{CH}), 7.22(\mathrm{dd}, 1 \mathrm{H}, \mathrm{CH})$.

MS (EI): $\mathrm{m} / \mathrm{z}(\%)=229.2(34), 214.2(100), 158.1(12), 144.1(29)$.

B) trans isomer: $0.99-1.77\left(\mathrm{~m}, 2 \mathrm{H}, \mathrm{CH}_{2}\right),\left(\mathrm{d}, \mathrm{J}=6.5,3 \mathrm{H}, \mathrm{CH}_{3}\right), 1.13(\mathrm{~m}, 1 \mathrm{H}, \mathrm{CH}), 1.19(\mathrm{~s}, 3 \mathrm{H}$, $\left.\mathrm{CH}_{3}\right), 1.33-1.83\left(\mathrm{~m}, 2 \mathrm{H}, \mathrm{CH}_{2}\right), 1.40(\mathrm{~m}, 1 \mathrm{H}, \mathrm{CH}), 1.42\left(\mathrm{~s}, 3 \mathrm{H}, \mathrm{CH}_{3}\right), 1.97(\mathrm{~m}, 1 \mathrm{H}, \mathrm{CH}), 3.16(\mathrm{dt}, 1 \mathrm{H}, \mathrm{CH})$, $3.69(\mathrm{bs}, \mathrm{NH}), 6.52(\mathrm{dd}, 1 \mathrm{H}, \mathrm{CH}), 6.73(\mathrm{~s}, 1 \mathrm{H}, \mathrm{CH}), 7.04(\mathrm{~m}, 1 \mathrm{H}, \mathrm{CH}), 7.04(\mathrm{~m}, 1 \mathrm{H}, \mathrm{CH}), 7.31(\mathrm{dd}, 1 \mathrm{H}, \mathrm{CH})$. MS (EI): $\mathrm{m} / \mathrm{z}(\%)=229.2$ (55), 214.2 (100), 158.1 (18), 144.1 (33).

\section{Conclusions}

The introduction of solid acid materials in organic synthesis is an ambitious target of green chemistry. Thus, a heterogeneous catalyst could be filtered off at the end of the reaction without the need of a neutralization step followed by washing and the time-consuming workup of the reaction mixture producing significant amounts of inorganic salts. N-containing heterocycles are the most abundant class of compounds synthesized by the pharmaceutical industry [28]. Here, we show that very simple inorganic materials such as Montmorillonite, that is a natural acidic clay, can effectively promote the synthesis of $\mathrm{N}$-containing octahydroacridines with a $92 \%$ yield in one hour and at room temperature, starting from anilines and citronellal, the main component of several essential oils. In some cases, yields were almost quantitative due to high selectivity with respect to the competing ene-reaction to isopulegols. Both high selectivity and the use of solid acid catalyst allowed us to obtain a negligible waste process, showing high sustainability.

Supplementary Materials: The following are available online at http://www.mdpi.com/2073-4344/8/10/410/s1, Figure S1: ${ }^{1} \mathrm{HNMR}$ of octahydroacridine obtained from citronellal and aniline.

Author Contributions: Conceptualization, F.Z. and N.R.; Investigation, F.S. and E.D.I.; Writing-Original Draft Preparation, F.Z.; Writing-Review \& Editing, N.R.; Supervision, N.R.

Funding: This research received no external funding.

Acknowledgments: Institut Atsiri Universitas Brawijaya, Malang, Indonesia is kindly acknowledged for a sample of Kaffir Lime essential oil.

Conflicts of Interest: The authors declare no conflict of interest.

\section{References}

1. Monteiro, J.L.F.; Veloso, C.O. Catalytic conversion of terpenes into fine chemicals. Top. Catal. 2004, 27, 169-180. [CrossRef]

2. Ravasio, N.; Zaccheria, F.; Guidotti, M.; Psaro, R. Mono- and bifunctional heterogeneous catalytic transformation of terpenes and terpenoids. Top. Catal. 2004, 27, 157-168. [CrossRef] 
3. Zhang, D.; del Rio-Chanona, E.A.; Shah, N. Screening synthesis pathways for biomass-derived sustainable polymer production. ACS Sustain. Chem. Eng. 2017, 5, 4388-4398. [CrossRef]

4. Wilbon, P.A.; Chu, F.; Tang, C. Progress in renewable polymers from natural terpenes, terpenoids, and rosin. Macromol. Rapid Commun. 2013, 34, 8-37. [CrossRef] [PubMed]

5. Kinanthi, R.; Puspitasari; Dwi, F.; Warsito, S.; Farid Rahman, M. Synthesis of schiff base from citronellal in kaffir lime oil (Citrus hystrix D.C) using acid catalyst. In Proceedings of the 1st International Conference of Essential Oils (ICEO2017), Malang, Indonesia, 11-12 October 2017.

6. Warsito; Ramadhan, S.D.; Al Karoma, D.; Zulfa, A. Comparison of synthesis of some benzimidazole derivatives of cytronellal and citral. In Proceedings of the 1st International Conference of Essential Oils (ICEO2017), Malang, Indonesia, 11-12 October 2017.

7. Kouznetsov, V.V. Recent synthetic developments in a powerful imino Diels-Alder reaction (Povarov reaction): Application to the synthesis of N-polyheterocycles and related alkaloids. Tetrahedron 2009, 65, 2721-2750. [CrossRef]

8. Canas-Rodriguez, A.; Canas, R.G.; Mateo-Bernardo, A. Tricyclic inhibitors of gastric acid secretion. Part, V. Octahydroacridines. An. Quim. Ser. C. 1987, 83, 24-27.

9. Mayekar, N.V.; Nayak, S.K.; Chattopadhyay, S. Two convenient one-pot strategies for the synthesis of octahydroacridines. Synth. Commun. 2004, 34, 3111-3119. [CrossRef]

10. Sakane, S.; Matsumura, Y.; Yamamura, Y.; Ishida, Y.; Maruoka, K.; Yamamoto, H. Olefinic cyclizations promoted by beckmann rearrangement of oxime sulfonate. J. Am. Chem. Soc. 1983, 105, 672-674. [CrossRef]

11. Sakanishi, K.; Mochida, I.; Okazaki, H.; Soeda, M. Selective hydrogenation of 9-aminoacridine over supported noble metal catalysts. Chem. Lett. 1990, 19, 319-322.

12. Kouznetsov, V.; Palma, A.; Rozo, W.; Stashenko, E.; Bahsas, A.; Amaro-Luis, J. A facile Brønsted acidic-mediated cyclisation of 2-allyl-1-arylaminocyclohexanes to octahydroacridine derivatives. Tetrahedron Lett. 2000, 41, 6985-6988. [CrossRef]

13. Jacob, R.G.; Perin, G.; Botteselle, G.V.; Lenardão, E.J. Clean and atom-economic synthesis of octahydroacridines: Application to essential oil of citronella. Tetrahedron Lett. 2003, 44, 6809-6812. [CrossRef]

14. Sabitha, G.; Reddy, E.V.; Yadav, J.S. Bismuth(III) Chloride: An efficient catalyst for the one-pot stereoselective synthesis of octahydroacridines. Synthesis 2002, 3, 409-412. [CrossRef]

15. Santoro, F.; Psaro, R.; Ravasio, N.; Zaccheria, F. Reductive amination of ketones or amination of alcohols over heterogeneous $\mathrm{Cu}$ catalysts: Matching the catalyst support with the N-Alkylating agent. ChemCatChem 2012, 4, 1249-1254. [CrossRef]

16. Zaccheria, F.; Scotti, N.; Marelli, M.; Psaro, R.; Ravasio, N. Unravelling the properties of supported copper oxide: Can the particle size induce acidic behaviour? Dalton Trans. 2013, 42, 1319-1328. [CrossRef] [PubMed]

17. Zaccheria, F.; Santoro, F.; Psaro, R.; Ravasio, N. CuO/SiO 2 : A simple and effective solid acid catalyst for epoxides ring opening. Green Chem. 2011, 13, 545-548. [CrossRef]

18. Scotti, N.; Dangate, M.; Gervasini, A.; Evangelisti, C.; Ravasio, N.; Zaccheria, F. Unraveling the role of low coordination sites in a $\mathrm{Cu}$ metal nanoparticle: A step forwards the selective synthesis of second generation biofuels. ACS Catal. 2014, 4, 2818-2826. [CrossRef]

19. Campanati, M.; Savini, P.; Tagliani, A.; Vaccari, A.; Piccolo, O. Environmentally friendly vapour phase synthesis of alkylquinolines. Catal. Lett. 1997, 47, 247-250. [CrossRef]

20. Ravasio, N.; Antenori, M.; Babudri, F.; Gargano, M. Intramolecular ene reaction promoted by mixed cogels. Stud. Surf. Sci. Catal. 1997, 108, 625-632.

21. Trombetta, M.; Busca, G.; Rossini, S.; Piccoli, V.; Cornaro, U.; Guercio, A.; Catani, R.; Willey, R. FT-IR studies on light olefin skeletal isomerization catalysis: III. surface acidity and activity of amorphous and crystalline catalysts belonging to the $\mathrm{SiO}_{2}-\mathrm{Al}_{2} \mathrm{O}_{3}$ system. J. Catal. 1998, 179, 581-596. [CrossRef]

22. Ravindra Reddy, C.; Bhat, Y.S.; Nagendrappa, G.; Jai Prakash, B.S. Brønsted and Lewis acidity of modified montmorillonite clay catalysts determined by FT-IR spectroscopy. Catal. Today 2009, 141, 157-160. [CrossRef]

23. Flessner, U.; Jones, D.J.; Rozière, J.; Zajac, J.; Storaro, L.; Lenarda, M.; Pavanc, M.; Jiménez-López, A.; Rodrìguez-Castellón, E.; Trombetta, M.; et al. A study of the surface acidity of acid-treated montmorillonite clay catalysts. J. Mol. Catal. A Chem. 2001, 168, 247-256. [CrossRef]

24. Vodnár, J.; Farkas, J.; Békássy, S. Catalytic decomposition of 1,4-diisopropylbenzene dihydroperoxide on montmorillonite-type catalysts. Appl. Catal. A 2001, 208, 329-334. [CrossRef] 
25. Laschat, S.; Lauterwein, J. Intramolecular hetero-Diels-Alder reaction of N-arylimines. Applications to the synthesis of octahydroacridine derivatives. J. Org. Chem. 1993, 58, 2856-2861. [CrossRef]

26. Acelas, M.; Romero Bohórquez, A.R.; Kouznetsov, V.V. Highly diastereoselective synthesis of new trans-fused octahydroacridines via. intramolecular cationic imino diels-alder reaction of $\mathrm{N}$-protected anilines and citronellal or citronella essential oil. Synthesis 2017, 49, 2153-2162.

27. Emeis, C.A. Determination of integrated molar extinction coefficients for infrared absorption bands of pyridine adsorbed on solid acid catalysts. J. Catal. 1993, 141, 347-354. [CrossRef]

28. Carey, J.S.; Laffan, D.; Thomson, C.; Williams, M.T. Analysis of the reactions used for the preparation of drug candidate molecules. Org. Biomol. Chem. 2006, 4, 2337-2347. [CrossRef] [PubMed]

2018 by the authors. Licensee MDPI, Basel, Switzerland. This article is an open access article distributed under the terms and conditions of the Creative Commons Attribution (CC BY) license (http://creativecommons.org/licenses/by/4.0/). 